\title{
Effect of Coconut Shell Ash and Graphite Particles on Microstructure and Mechanical Properties of Recycled Aluminium Composites
}

\author{
Adekunle Adetayo Yekinni' ${ }^{1}$, Solomon Kola Bello ${ }^{2}$, Gideon Gbenga Bajela ${ }^{3}$, \\ Ismaila Adeniyi Adigun ${ }^{4}$
}

Research Scholars, Department of Mechanical Engineering, Lagos State Polytechnic, Ikorodu, Lagos ${ }^{1-4}$

Nigeria

\begin{abstract}
The current high demand for aluminium (Al) matrix composites with improved physical and mechanical properties has resulted in growing concern in the production of hybrid composites of aluminium at a lower cost. In the present work, an effort has been made to develop a hybrid aluminium matrix composite from waste aluminium cans, coconut shell ash (150 $\mu \mathrm{m})$ and graphite (150 $\mu \mathrm{m})$ particles by stir casting method. Composites were prepared by reinforcing recycled aluminium alloy with a combination of 0,2,4,6,8 \% weight (wt.) fraction of coconut shell ash (CSA) and constant $2 \%$ wt. the fraction of graphite. The cast produced were machined in accordance with ASTM standard into an appropriate coupon for microstructural examination, density measurement, tensile, impact and hardness tests. The micrograph showed reasonably uniform distribution of CSA and graphite particles in the matrix of aluminium alloy. Casting defects such as shrinkage did not manifest and porosity are minimal. The results also revealed a reduction in density and impact energy within the range of 2.46-2.23 g/cm3 and 12.92-4.76 J respectively. Hardness and tensile strength increased within the range of 220.9-266.4 HV and 27-57 M. Pa respectively. The result reveals that, overall reduction of density and impact strength together with improved hardness and ultimate tensile strength of the composites. The control sample, confirmed the retention of the reinforcements in the aluminium matrix. This study has affirmed the suitability of recycled aluminium cans reinforced with graphite and coconut shell ash as a candidate material for the production of the most common automobile part.
\end{abstract}

Keywords: Coconut shell ash, Graphite, Recycled aluminium cans, Reinforcement, Hybrid composite.

\section{INTRODUCTION}

The limited mechanical properties of aluminium and its alloys is believed to have adverse effects on its use in automobile, aerospace and other industries applications [1-3]. Researches on aluminium and its alloys that are carried out to improve its mechanical properties involve incorporating different forms of reinforcements into the aluminium matrices depending on the expected mechanical properties. The increase in requirements of materials having high specific mechanical properties coupled with weight savings characteristic has resulted in significant research activities in recent times with special attention on further development of aluminium-based composites [4-6]. Such distinctive properties as high stiffness, high strength and low density have promoted an increasing number of applications for these materials in automobile and aerospace. Recent demand for aluminium as structural materials to be cost effective and also to provide high performance has also resulted in continuous efforts being made particularly in areas of alloy design and the use of novel processing techniques to develop composites that will compete favourably with monolithic and traditional aluminium alloys [7]. Growing interest of researchers has been drawn to the use of agro waste as secondary reinforcement in composite fabrication. This was in an attempt to overcome the limitations from the high cost of metal matrix composites (MMCs); resulting from interfacial reactions and high density of the most commonly used ceramic reinforcements compared to aluminium alloys [8-10]. The presence of high contents of silica and heamatite in most agro-waste makes their use desirable as reinforcements $[11,12]$. However, coconut shell ash has $\mathrm{SiO}_{2}$ as one of the principal constituent $[13,14]$. Coconut shell is known to be an agro-waste and it is readily available in large quantity in Nigeria. Traditionally, it is locally used as fuel for cooking in most part of Nigeria. It also serves as a source of fuel, most especially for the black smith for forging process. Alaneme et al., [15] observed in his study, the significance of investigating the corrosion behaviour of aluminium matrix composites as a way of expanding its areas of applications. Synthetic graphite and coconut shell 
ash (an agro waste) are typical reinforcements that could be used to tailor the mechanical properties of recycled aluminium alloy towards certain objectives. In automobile field where metal with good resistance to corrosion/wear and improved mechanical properties are required, aluminium composites are used to produce components and parts such as pistons, brake drum and cylinder block [8,12]. Synthetic graphite is a man-made essence which is deliberately created by the heavy temperature processing of amorphous carbon materials and it is the most stable form of carbon under standard conditions. Graphite can be described as a crystal-like allotrope of carbon, a semi metal, a native element mineral, and a form of coal. Aluminum-Graphite composite combines the benefits of high thermal conductivity of metal and low coefficient of thermal expansion (CTE) of ceramic [16]. Coconut shell ash within the range of $2-8 \%$ by weight was reinforced in aluminium alloy by [17,18], to achieve a significant improvement on the mechanical, tribological properties and machining of the composites. In recent years there has been an incredible interest in composites containing low density and low cost reinforcements. Among various reinforcements which have been used, coconut shell ash is one of the most inexpensive and low density reinforcement which also available in large quantities as solid waste by-product. Aluminium composite reinforced with coconut shell ash particles exhibit wear resistance, increased hardness and decrease in density (reduced weight) and improved strength and stiffness when compared with various monolithic matrix materials [3,19-24].

Production of hybrid composites of Aluminium from synthetic and agro wastes reinforcements had been attempted by various researchers with a view to fabricating aluminium composites of improved mechanical properties not obtainable from monolithic aluminium and single reinforcement. Yekinni et al., [25] suggested that with appropriate processing method and process parameters of careful choice, combination of an agro waste and carbon nanoparticles could bring about better improvement in the mechanical properties and widen the automotive application areas of aluminium composite. Further work by Yekinni et al., [26] revealed some significant improvements in morphological, mechanical and physical properties of recycled aluminium alloy reinforced with rice husk ash and graphene.

Subramaniam et al., [27] investigated Aluminium 7075 alloy reinforced with particles of boron carbide $\left(\mathrm{B}_{4} \mathrm{C}\right)$ and coconut shell fly ash fabricated by stir casting method. The weight percentages of $\mathrm{B}_{4} \mathrm{C}$ was varied at $0,3,6,9$ and 12 wt. $\%$ while coconut shell fly ash was kept constant at $3 \mathrm{wt} . \%$. Gradual increase in hardness was obtained up to $12 \mathrm{wt}$. $\% \mathrm{~B}_{4} \mathrm{C}$ while highest tensile strength was obtained at $9 \mathrm{wt} \%$ of $\mathrm{B}_{4} \mathrm{C}$. Increasing $\mathrm{B}_{4} \mathrm{C}$ and CSFA reinforcements in the matrix resulted in decrease in elongation of the composites. The impact energy of $2.3 \mathrm{~J}$ was achieved with $9 \mathrm{wt} . \% \mathrm{~B}_{4} \mathrm{C}$ and $3 \mathrm{wt} . \% \mathrm{CSFA}$ addition in aluminium alloy.

Rajesh et al [28] developed a hybrid composites from Aluminium alloy Al6061 reinforced with Boron carbide and Coconut shell ash. The study obtained revealed aluminium composite with superior properties such as strength, hardness, wear and corrosion resistance.

Nithyanand et al [29] successfully developed from aluminium (6060) alloy, a hybrid composites from varying percentage weight fraction of $\mathrm{B}_{4} \mathrm{C}$ and coconut shell ash using stir casting technique. The results indicated increase in the value of tensile strength and hardness with increase in weight percentage of reinforcements.

In order to reduce the weight of clutch plate material without affecting its life and effectiveness, [30] fabricated aluminium composite (Al-SiC-CSA) with 92 wt. \% Al alloy, 5 wt.\% SiC and 3wt. \% coconut shell ash. A durable composite with low density and high strength was obtained.

Poornesh et al [31] studied the effect of varying percentages of coconut shell ash and SiC particles on mechanical properties of aluminium alloy prepared by stir cast method. The results revealed that the addition of ash and ceramic particles have a significant influence in the mechanical properties but could make the composites brittle.

Effect of bagasse ash and graphite with different percentages reinforcement in Al7075 as matrix material was investigated by [32]. The results indicated that the ultimate tensile strength and hardness increases whereas there was decrease in the percentage elongation with increase in wt. \% of bagasse ash and graphite.

The Authors are of the view that it is possible from outcome of previous researches to combine properties (such as high thermal conductivity, low coefficient of thermal expansion, and machinability) obtained for Al/graphite composites with properties (such as good wear resistance, increased hardness and decrease in density and improved strength and stiffness) obtained for Al/CSA to produce a hybrid composites of Al/graphite/CSA. This paper shows an experimental report of the effect of coconut shell ash and graphite on density, tensile strength, impact energy and hardness of a recycled aluminium cans. 


\section{MATERIALS AND METHODS}

\subsection{Materials}

In this study, waste aluminium cans were used as matrix while coconut shell ash and graphite, both at $150 \mu \mathrm{m}$ particles size were used as reinforcements.

\subsection{Equipment}

Melting and production of casting was carried out in a diesel fired crucible furnace, oven and muffle furnace were used to dry and burn the reinforcements. Tensile, impact and microhardness testing machines were also used to determine the mechanical properties. Microscopic analysis and composition were determined using optical microscope machine, X-ray fluorescent XRF respectively.

\subsection{Materials Preparation}

\subsubsection{Preparation of Aluminium Alloy (Matrix)}

Disposed aluminium cans was charged into the crucible pot of the oil-fired crucible furnace. About $20 \mathrm{Kg}$ of compressed aluminium cans were heated and melted at about $850^{\circ} \mathrm{C}$ in a continuous process. The furnace was left open while the scraps were being charged into the pot. The charge was properly stirred by the use of a long metal rod.

After subsequent charging, the crucible pot became filled-up with molten aluminium. The pot was carried out of the furnace by the use of tong. The molten metal in the pot was thoroughly turned to remove the slag. After which it was degassed to prevent blow holes in the cast billet by dropping some piece of aluminium cans into the molten metal.

The molten metal was then poured in an open metal cavity mould and allowed to air cool. This was later removed from the metal mould as aluminium billet. The sequence of operation was repeated until the scrap was completely melted. Each aluminium billet gotten from the scrap was re-charged into the furnace and re-melted for homogenization since the waste aluminium cans were obtained from different sources.

\subsubsection{Preparation of Coconut shell ash reinforcement particles}

The collected coconut shell was sourced locally within Ikorodu area, washed with water to remove impurities and dried in an oven at about $100^{\circ} \mathrm{C}$ to reduce its moisture content. It was then crushed with hammer and grinded to form coconut shell powder. The powder was packed and lagged with cotton wool in a graphite crucible pot and fired in an electric muffle furnace in the absence of air to a temperature of $450^{\circ} \mathrm{C}$ and held for about $8 \mathrm{hrs}$ to form carbonized coconut shell ash. The particle size of the ash was further reduced by ball milling for about $16 \mathrm{hrs}$ in accordance with [33]. A set of sieves was used to obtain a $150 \mu \mathrm{m}$ particle size of the CSA.

\subsubsection{Preparation of Graphite (Reinforcement)}

The purchased graphite was grinded and sieved into $150 \mu \mathrm{m}$ particle size.

\subsubsection{Preparation of Hybrid Composites from Aluminum Alloy, Coconut Shell Ash and Graphite}

Homogenized aluminum billet was melted in furnace at about $750^{\circ} \mathrm{C}$. A pre-heated graphite of $2 \%$ wt. was introduced gradually into the molten aluminum while still in the furnace. After graphite addition, the liquid metal-reinforcement mixture was stirred for 2 minutes manually, and thereafter returned into the furnace. The pre-heated biodegradable reinforcement (CSA) was added through the top-bottom method (at $0 \%, 2 \%, 4 \%, 6 \%$ and $8 \%$ ). The molten metal was 
poured in appropriate coupon, allowed to solidify and machined to produce various test specimens. The composites were prepared using the configuration in table 1.1

Table 1.1. Test coupon formulation

\begin{tabular}{|c|c|}
\hline Samples & Composition \\
\hline 1 & $\mathrm{Al}$ \\
\hline 2 & $\mathrm{Al}+2$ wt. \% graphite \\
\hline 3 & $\mathrm{Al}+2$ wt.\% CSA +2 wt. \% graphite \\
\hline 4 & $\mathrm{Al}+4$ wt. \% CSA + 2 wt. \% graphite \\
\hline 5 & $\mathrm{Al}+6$ wt. \% CSA + 2 wt. \% graphite \\
\hline 6 & $\mathrm{Al}+8$ wt. \% CSA + 2 wt. \% graphite \\
\hline
\end{tabular}

\subsection{Determination of Chemical Compositions}

Specimen was prepared for chemical compositions of the control aluminium alloy sample. Hilger Analytical Direct Optical Light Emission Polyvac Spectrometer, Model E980C. Shimadzu XRF-1800 was used to determine the composition of coconut shell ash. The tests were conducted at Spectrum Analytical Facility, Department of Physics, University of Johannesburg, South Africa.

\subsection{Optical Micrographs}

Optical microscope was used to provide basic information about the microstructure of the samples. The samples were cut from the control sample and five composites. The cut samples were mechanically ground progressively using StruersTegraPol 25Grinding and Polishing Machine on grades of SiC impregnated emery paper (80-600 grits) sizes using water as the coolant. The ground samples were polished using one-micron size alumina polishing powder suspended in distilled water.

Final polishing was achieved using 0.5-micron alumina polishing powder suspended in distilled water. Following the polishing operation, etching of the polished sample was done using Keller's reagent. The microstructure and the chemical compositions of the phases present in the test samples were studied using a 3000-inverted metallurgical optical microscope [25].

\subsection{Preparation of specimens and testing}

Standard specimen of dimensions $50 \times 10 \times 10 \mathrm{~mm}$ were made as sample pieces. The mass of the control sample specimen and each composite specimen was determined using digital Pioneer weighing balance by Ohaus Corporation, USA and density measurement taken for samples in accordance with [25].

The Vickers diamond test was done on Vickers hardness tester (LECO AT700 Micro Hardness Tester). Three hardness tests were performed on each sample at three different positions of interest on the hardness specimen and the average of the best values taken as a measure of the microhardness.

The tensile test specimen was prepared on a lathe machine to determine the tensile strength following standard test procedures in accordance with the American Society for Testing and Materials E8 (2008). The tensile test was carried out at room temperature with samples of initial $40 \mathrm{~mm}$ gauge length and diameter $6 \mathrm{~mm}$ subjected to tensile test using Instron Extensometer, (model: Instron 3369), system ID: 3369S3457. This procedure was in line with [25].

The impact energy specimen was prepared in accordance to ASTM A370 standard specimen size for Charpy impact testing. The impact energies of the control sample and produced composites were measured with the aids of Avery Denison Universal Impact Testing Machine. 


\subsection{RESULTS AND DISCUSSION}

\subsection{Chemical composition of Al matrix and coconut shell ash}

Elemental composition of the unreinforced aluminium alloy billet (matrix) and chemical compound composition of coconut shell ash are shown in Tables 1.2 and 1.3 respectively.

Table 1.2 shows that major elements in the recycled $\mathrm{Al}$ alloy used as control sample apart from $\mathrm{Al}$ according to the composition analysis are $\mathrm{Si}, \mathrm{Cu}, \mathrm{Mn}, \mathrm{Zn}$ and Ti. These elements are expected to influence the phase reactions that will be revealed when reinforcements are added at various percent weight fraction and particle sizes. The presence of these elements may also affect the physical and mechanical properties of the developed composites. X-Ray fluorescence (XRF) analyser also revealed chemical compositions of RHA which are shown in Table 1.3 Compounds such as $\mathrm{SiO}_{2}$ (Silicon oxide), $\mathrm{Al}_{2} \mathrm{O}_{3}$ (Aluminium oxide), $\mathrm{MgO}$ (Magnesium Oxide) and $\mathrm{FeO}$ (Iron Oxide) are the major constituents while $\mathrm{CaO}$ (Calcium oxide) and $\mathrm{K}_{2} \mathrm{O}$ (Potassium oxide), $\mathrm{Na}_{2} \mathrm{O}$ (Sodium Oxide) and $\mathrm{MnO}$ are minor constituents of the CSA. The oxides like $\mathrm{SiO}_{2}, \mathrm{Al}_{2} \mathrm{O}_{3}$ and $\mathrm{FeO}$ make the matrix harder and more durable which may result in improved mechanical properties. $\mathrm{Al}_{2} \mathrm{O}_{3}$ and $\mathrm{SiO}_{2}$ are well-known reinforcing additives for improving wear resistance and strength for $\mathrm{Al}$ composites. $\mathrm{CaO}$ could react with alumina and silica to form aluminates and calcium silicates, which have good adhesive properties and improve the load bearing capability of the composites [23,34]. $\mathrm{MgO}$ is a refractory material, which can withstand high temperature and has a low thermal conductivity [35].

Table 1.2. The elemental composition (wt.\%) of the unreinforced cast aluminium alloy ingot (control sample)

\begin{tabular}{llllllllll}
\hline $\mathbf{A l}$ & $\mathbf{S i}$ & $\mathbf{F e}$ & $\mathbf{C u}$ & $\mathbf{M n}$ & $\mathbf{M g}$ & $\mathbf{Z n}$ & $\mathbf{P}$ & $\mathbf{N i}$ & $\mathbf{T i}$ \\
\hline 94.0218 & 0.825 & 0.332 & 1.065 & 0.770 & 0.0046 & 2.014 & 0.021 & 0.053 & 0.912 \\
$\mathbf{S}$ & $\mathbf{C r}$ & $\mathbf{S n}$ & $\mathbf{M o}$ & & & & & & \\
\hline 0.016 & 0.005 & 0.0023 & 0.006 & & & & & & \\
\hline
\end{tabular}

Table 1.3. Chemical compound (wt.\%) composition of Coconut shell ash burnt at $450^{\circ} \mathrm{C}$

\begin{tabular}{ccccccccc}
\hline $\mathbf{S i O}_{\mathbf{2}}$ & $\mathbf{A l}_{\mathbf{2}} \mathbf{O}_{\mathbf{3}}$ & $\mathbf{F e O}$ & $\mathbf{M g O}$ & $\mathbf{M n O}$ & $\mathbf{K}_{\mathbf{2}} \mathbf{O}$ & $\mathbf{N a}_{\mathbf{2}} \mathbf{O}$ & $\mathbf{Z n O}$ & $\mathbf{L O I}$ \\
\hline 48.213 & 15.234 & 12.673 & 16.574 & 0.625 & 1.811 & 0.892 & 0.472 & 3.206 \\
\hline
\end{tabular}

\subsection{Optical microscopy}

The optical micrograph and SEM showed reasonably uniform distribution of CSA and graphite particles in the matrix of aluminium alloy. The distribution of the particles throughout the matrix is found to be fairly uniform resulting in composites with isotropic property. However, casting defects such as shrinkage did not manifest and porosity are minimal.

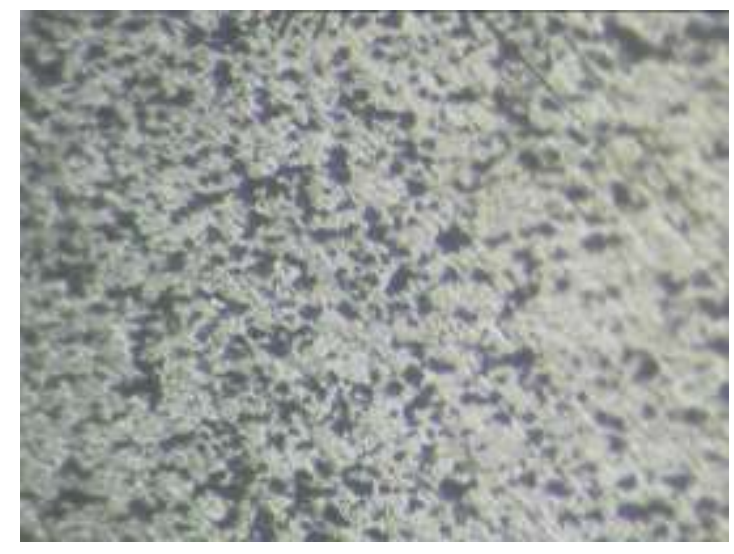

(a)

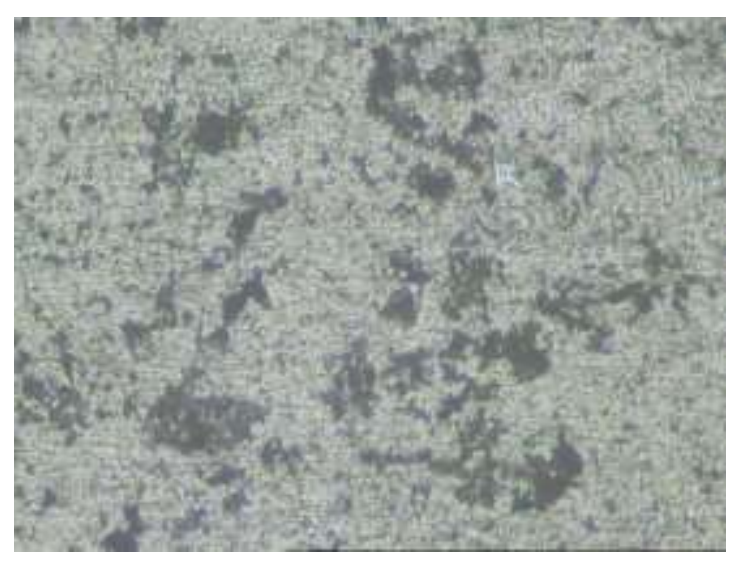

(b) 


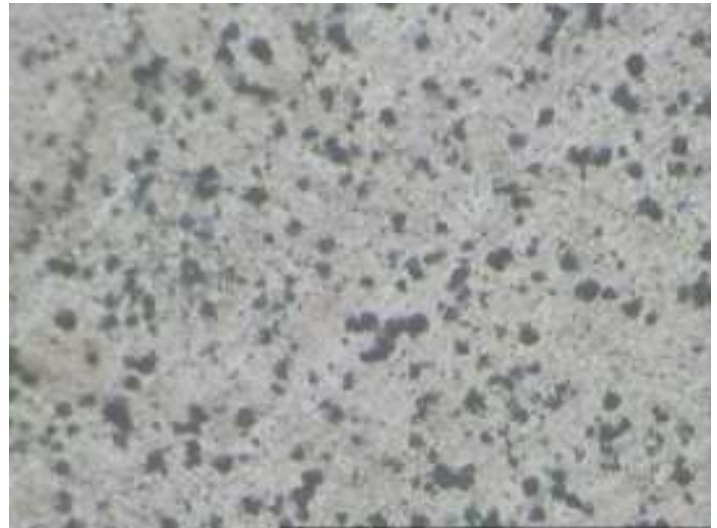

(c)

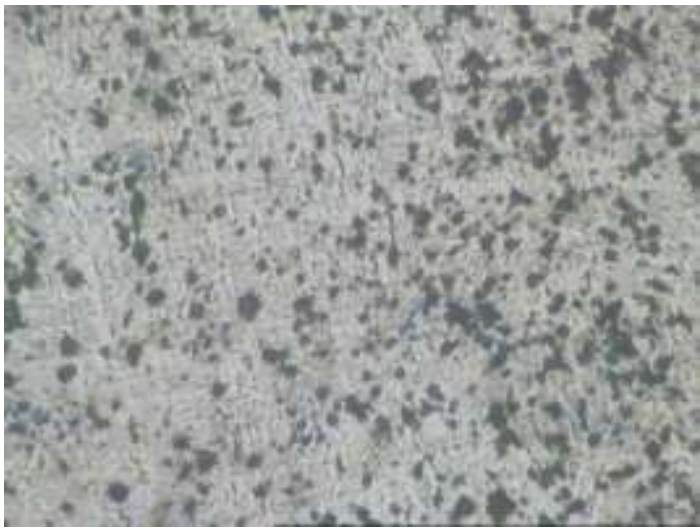

(e)

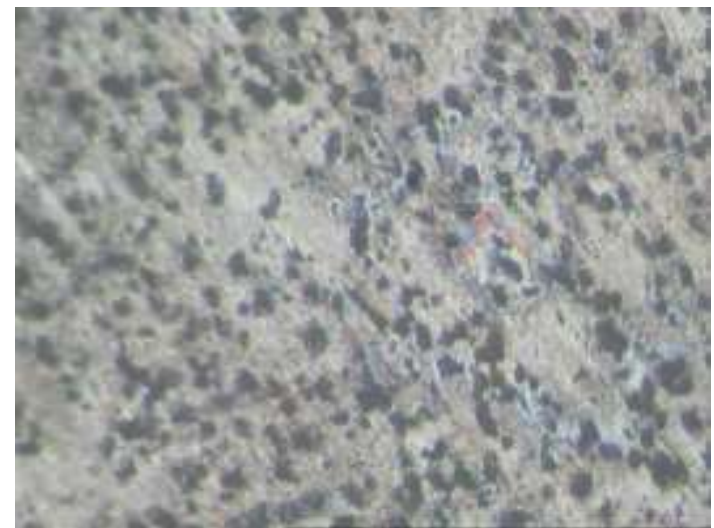

(d)

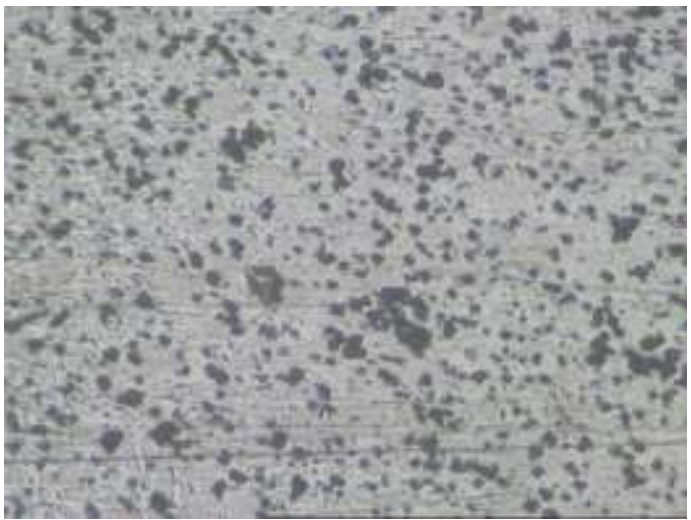

(f)

Figure 1.1 Optical microscopy (a) Control sample (b) 98 wt. \% Al, 0 wt. \% CSA, 2 wt. \% Graphite (c) 96 wt. \% Al, 2 wt. \% CSA, 2 wt. \% Graphite (d) 94 wt. \% Al, 4 wt. \% CSA, 2 wt. \% Graphite (e) 92 wt. \% Al, 6 wt. \% CSA, 2 wt. \% Graphite (f) 90 wt. \% Al. 8 wt. \% CSA, 2 wt. \% Graphite.

\subsection{Physical and Mechanical properties}

Figures 1.2 to 1.5 show the results for density, microhardness, ultimate tensile strength, and impact strength of the control sample and composites respectively. The mechanical properties of the composites were greatly influenced by the presence of other metallic elements apart from $\mathrm{Al}$ as shown in the elemental composition of the unreinforced aluminium alloy in table 1.2. Such metallic elements include $\mathrm{Zn}$ (2.014), $\mathrm{Cu}$ (1.065), $\mathrm{Ti}$ (0.912) and $\mathrm{Mn}(0.770)$.

The results in figure 1.2 showed that the density decrease as the weight percent of reinforcements increases. An average percent reduction of about $1.94 \%$ was obtained while overall reduction of $9.35 \%$ was obtained when the density of the composite at $2 \%$ graphite and 8 wt. \% CSA was compared with the control sample. The decrease in densities is believed to have resulted from the hard and lower density coconut shell ash and graphite addition which replaces the soft and higher-density aluminium matrix in the composites thereby giving the composites overall reduction in densities. Figure 2 shows the graphs of density against control sample and composites.

The improvement in the ultimate tensile strength (UTS) as obtained in figure 1.3 when graphite and CSA were added to the aluminium matrix is believed to be due to the high rate of diffusion of reinforcements and their deep penetration into the matrix of $\mathrm{Al}$ alloy, forming a good interfacial adhesion between the Al matrix, graphite and CSA. Increased packing density of each of the reinforcement which were uniformly dispersed throughout the Al matrix could have also contributed to the increase in the tensile strength. Effect of graphite on the gradual increase in tensile strength can be noticed due to the highest percent increase in tensile strength of about $22 \%$ during addition of only 2 wt. \% graphite and $0 \%$ CSA when compared to the control sample. This increase was in line with [18] which obtained the highest increase in tensile strength of aluminium composite at $4 \mathrm{wt}$ \% addition of graphite. However, tensile strength 
increases progressively upon addition of CSA at interval of $2 \mathrm{wt}$ \% increase in CSA. Overall percent increase of about $70 \%$ was achieved at 2 wt. $\%$ G, 8 wt. \% CSA when compared with the control sample.

Figure 1.4 gives the variation of hardness value of the test samples. An increasing trend of hardness is observed with increase in weight fraction of coconut shell ash mixed with graphite. It is observed that the fact that the combination of fixed amount of graphite with varying percent coconut shell ash particles possess higher hardness than unreinforced aluminium. This is because graphite particles have higher density and are hard. The coconut shell ash particles have various hardening elements as shown in the XRF. Due to which the mixture has higher hardness compared to unreinforced aluminium. Further observations clearly showed that the hardness of the composite increases with increase in weight fraction of the reinforcements. This reason is attributed to increases in surface area of the matrix which then reduces the grain sizes. Also, the presence of reinforcing particles with such hard surface area offers more resistance to plastic deformation and then, increase hardness. It can also be inferred that the resistance of the composites to surface indentation increased with increased addition of the reinforcements within the $\mathrm{Al}$ matrix. The presence of graphite particles in the composite might have taken the load acting on it. Owing to the higher density and higher hardness of the graphite particles, the load acting on the composites will be nullified [31]. It is also very clear from figure 1.4, that an increase of $10.5 \%$ in the hardness between the control sample and composite with only $2 \%$ graphite is obtained with successive increase of $6.3 \%, 2.3 \%, 3.8 \%$ and $3.3 \%$ between the other compositions.

The impact energy shown in figure 1.5 decreases as the reinforcement wt. \% increases. The decrease in impact energy may be attributable to extreme hardness of the new phases which imparts brittleness to the Al matrix. Also, the porosity free-coarse fibrous grain microstructure of the control sample could have hindered crack growth, leading to absorption of higher impact energy than at reinforced composites. Hence, the addition of reinforcements to the $\mathrm{Al}$ matrix enhanced the strength and grain refinement but reduced the impact energy. Highest reduction of impact energy of about $30 \%$ was noticed at 2 wt. \% graphite, 8 wt. \% CSA and 90 wt. \% Al. in each case, there will be a decrease in toughness of the hybrid composites due to the presence of the ceramic reinforcement particles. The addition of the ceramic reinforcement particles tends to improve its strength under the slow loading conditions as in the case of tensile test. But under the sudden loading applied during to the impact test, due to its inherent brittleness the reinforcing particles fails to impart the strength to its matrix material [31].

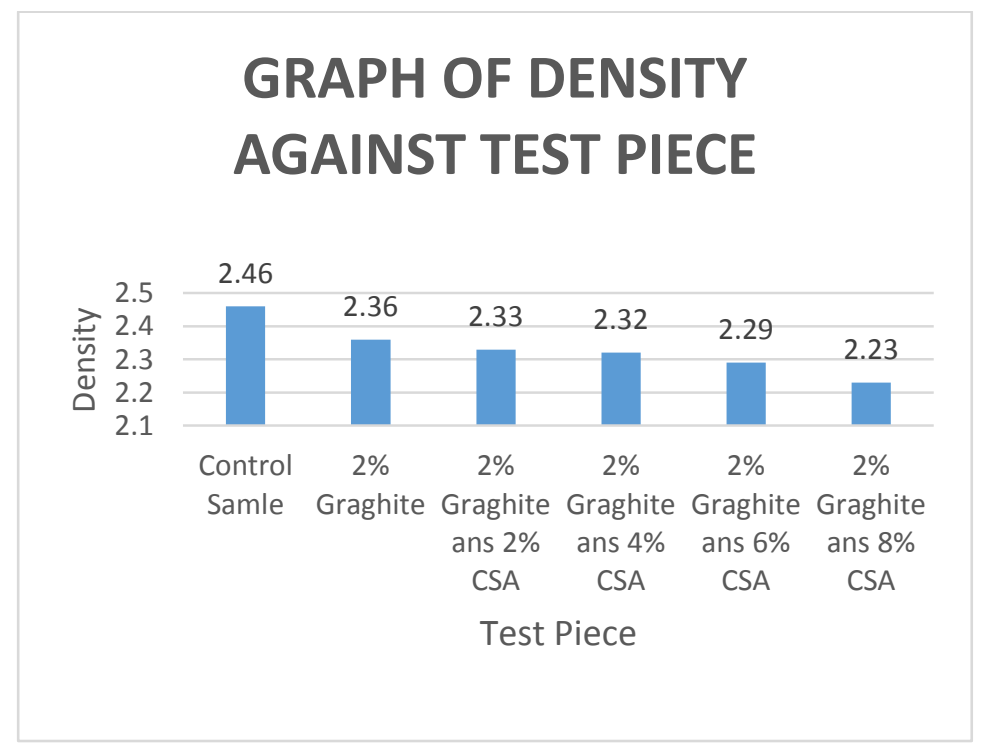

Figure 1.2 Density versus \% wt. fraction 


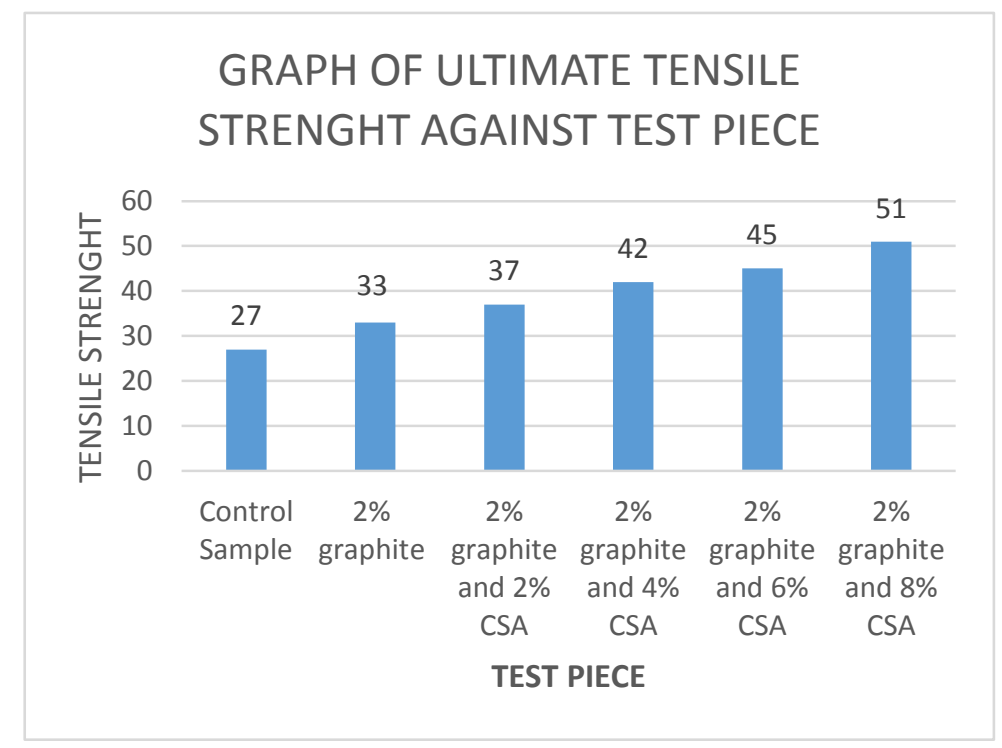

Figure 1.3. Ultimate tensile strength versus \% wt. fraction

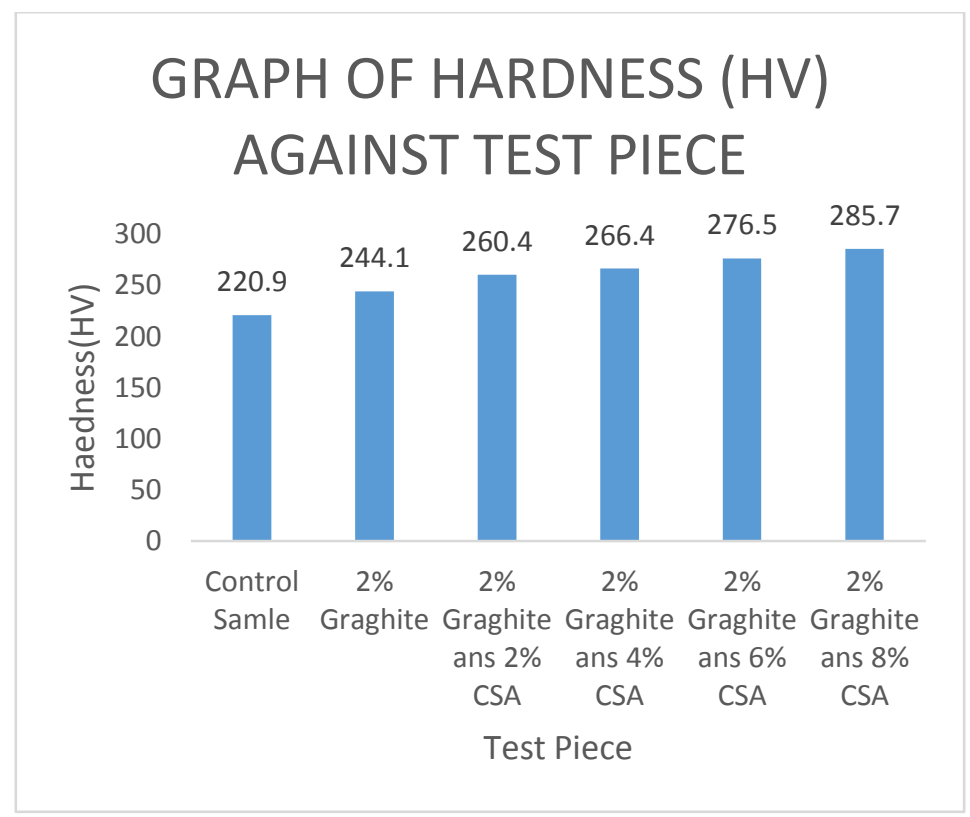

Figure 1.4. Graph of hardness versus \% wt. fraction 


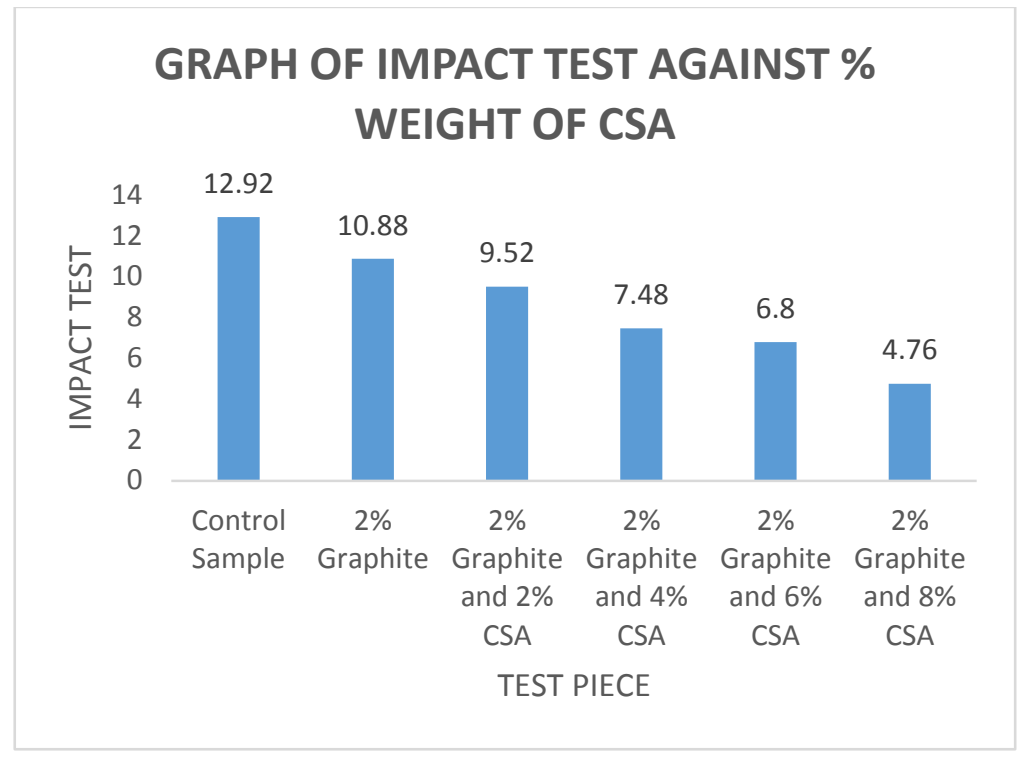

Figure 1.5. Graph of impact test versus \% wt. fraction

\section{CONCLUSION}

The following conclusions can be drawn from the present study:

i. The hybrid composite was successfully cast from recycled aluminium cans using the stir casting technique with graphite and CSA at $150 \mu \mathrm{m}$ particles size as reinforcement

ii. The micrograph of the composites showed reasonably uniform distribution of CSA and graphite particles in the matrix of aluminium alloy. Casting defects such as shrinkage did not manifest and porosity are minimal.

iii. The tensile tests results revealed that, with the increase of the reinforcements in the Al matrix, the UTS increases significantly when compared the control sample with the composite at 2 wt. \% graphite and 8 wt. \% CSA. Total increase of about $89 \%$ was obtained with average increase of about $14 \%$.

iv. A noticeable increase in hardness from $220.9 \mathrm{HV}$ to $285.7 \mathrm{HV}$ was obtained, representing a total increase of about $70 \%$ when the composite was reinforced with 2 wt. \% graphite and 8 wt. \% CSA.

v. The impact energy as well as the density of the composites exhibited a decreasing trend in the result because of the inherent properties demonstrated by the additives.

vi. The composites produced from recycled aluminium cans reinforced with graphite and coconut shell ash are suitable as candidate materials for the production of most common automobile parts.

\section{Acknowledgments}

The authors wish to acknowledge the financial support by the Tertiary Education Trust Fund (TETFunD) to carry out this research work. We also appreciate the Management, Dean of Schools and TETFunD Desk officer, Lagos State Polytechnic, Ikorodu for the administrative efforts provided to facilitate release of the fund.

\section{REFERENCES}

[1] M.O Lai. "Development of ductile Mg composite material using Ti reinforcement", Journal of Materials Sciences, $2009, \mathrm{Vol}$. 31, pp 2155-2167.

[2] C.R. Wang. and J.M Yang. "Materials characterization by scanning electron microscopy", Mater. Chem. Phys., 2002, Vol. 14, pp 272-286.

[3] J.O Agunsoye, S.I Talabi, S.A Bello and I.O Awe. "The Effects of Cocos Nucifera (Coconut Shell) on the Mechanical and Tribological Properties of Recycled Waste Aluminium Can Composites”. Tribology in Industry. 2014, Vol. 36. No 2, pp 155162.

[4] K. Ajoy Kumar Ray, S.K Venkateswarlu, S.K Chaudhury, B. Das, and I.C Ravi Kumar: "Fabrication of TiN reinforced aluminium metal matrix composites through a powder metallurgical route", Materials Science and Engineering A, $2002, \mathrm{Vol}$. 338, pp 160-165.

[5] J.C Walker, W.M Rainforth and H. Jones. "Lubricated sliding wear behaviour of aluminium alloy composites", Wear, 2005 Vol. 259, pp 577-589.

[6] H. Joel. "Development and property evaluation of aluminum alloy reinforced with nano- $\mathrm{ZrO}_{2}$ metal matrix composites (NMMCs)", Materials Science and Engineering A, 2009, Vol. 507, pp 110-113. 
[7] C. Lorella and M. Roberto. Advances in Metal Matrix composites, Trans Tech Publications, Inc, 2011, ISBN-13: 978-3-03785057-2, 170 .

[8] O.A. Olugbenga and A.A. Akinwole. "Characteristics of bamboo leaf ash stabilization on lateritic soil in highway construction". International Journal of Engineering and Technology, 2010, 2, pp 212-219.

[9] S.D Prasad and R.A. Krishna, "Tribological properties of A356.21RHA composites". Journal of Material Science and Technology, 2012, 28, pp 367-372.

[10] H. Zuhailawati, P. Samayamutthirian, and C.H. Mohd Haizu. "Fabrication of low cost aluminum matrix composite reinforced with silica sand". Journal of Physical Science, 2007, 18, pp 47-55.

[11] D.S. Prasad, C. Shoba and N. Ramanaiah. "Investigations on mechanical properties of Al hybrid composites", Journal of Material Research and Technology, 2014, 3(1), pp 79-85.

[12] S. Valdez, B. Campillo, R. Perez, L. Martinez and H. Garcia." Synthesis and microstructural characterization of Al-Mg alloySiC particulate composite", Materials Letters, 2008, 62(17-18), pp 2623-2625.

[13] A. Apasi, P.B. Madakson, D.S. Yawas and V.S.Aigbodion. "Wear behaviour of Al-Si-Fe alloy/coconut shell ash particulate composites", Tribology in Industry, 2012, 34(1), pp 36-43.

[14] K.K Alaneme, P.A. Olubambi, A.S. Afolabi and M.O. Bodunrin. "Corrosion and Tribological Studies of Bamboo Leaf Ash and Alumina Reinforced Al-Mg-Si alloy matrix hybrid composite in chloride medium", International Journal of Electrochemical Science., 2014, 9, pp 5663-5674.

[15] K.K Aleneme, H.I. Eze and M.O. Bodunrin." Corrosion behaviour of groundnut shell ash and silicon carbide hybrid reinforced Al-Mg-Si alloy composites in 3.5\% NaCl and $0.3 \mathrm{M} \mathrm{H}_{2} \mathrm{SO}_{4}$ ", Leonardo Electronic Journal of Practices and Technologies, 2015, 26, pp 129-146.

[16] A.M Davidson and R.D.A Regener. "Comparison of aluminium-based metal-matrix composites reinforced with coated and uncoated particulate silicon carbide”.. Composites Science and Technology. 2000, Volume 60, Issue 6, pp 865-869.

[17] L. Shankar, K.C. Anil and P.J Karabasappagol. "A Study on Effect of Graphite Particles on Tensile, Hardness and Machinability of Aluminium 8011” Matrix Material IOP Conf. Series: Materials Science and Engineering 149,2016012060 doi:10.1088/1757-899X/149/1/012060 pp 1-8.

[18] A. Kumari and P. Kumara. "Analysis of Graphite reinforced Aluminium-6061 Metal Matrix Composite using Stir Casting Method”, International Journal of Applied Engineering Research 2018, ISSN 0973-4562 Volume 13, Number (C) Research India Publications. http://www.ripublication.com pp 189-193.

[19] K. Varalakshmi, K.K. Kumar, P.R. Babu, and M.R. Sastry. "Characterization of Al 6061- Coconut Shell Ash metal matrix composites using Stir Casting”. International Journal of Latest Engineering Science (IJLES), 2019, E-ISSN: 2581-6659, Volume: 02 Issue: 03 pp 41-50.

[20] H. Mohanty, S.S Chowdhury, B.K Rout, S.K Panda, S.S Biswal and R.S.S Raju. "Study on Mechanical and Machinability Properties of Aluminium Coconut shell ash by Taguchi Approach". International journal of innovative research in technology, 2017 | IJIRT | Volume 3 Issue 11 | ISSN: 2349-6002 pp 68-74.

[21] A.K. Kumar, K.S Kumar' and R.S.S. Raju. "Study of Physical, Mechanical and Machinability Properties of Aluminium Metal Matrix Composite Reinforced with Coconut Shell Ash particulates". Imperial Journal of Interdisciplinary Research (IJIR), 2016, Vol-2, Issue-5, pp 151-157.

[22] P.B Madakson, D.S Yawas and A.Apasi. "Characterization of Coconut Shell Ash for Potential Utilization in Metal Matrix Composites for Automotive Applications", International Journal of Engineering Science and Technology (IJEST), 2012, Vol. 4 No.03., pp 1190-1198.

[23] R.S.S Raju and G.S Rao. "Assessment of Tribological Performance of Coconut Shell Ash Particle Reinforced Al-Si-Fe Composites using Grey-Fuzzy Application”. Tribology in Industry. 2017, Vol. 39, No 3, pp 364-377.

[24] O.O Daramola, A.A Adediran and A.T Fadumiye. "Evaluation of the mechanical properties and corrosion behaviour of coconut shell ash reinforced aluminium (6063) alloy composites". Leonardo Electronic Journal of Practices and Technologies, 2015, Issue 27, ISSN 1583-1078, pp 107-119.

[25] A.A Yekinni,, M.O Durowoju, J.O Agunsoye and L.O Mudashiri..” Effects of rice husk ash and graphene on morphological and mechanical properties of recycled aluminium cans hybrid composites". Science Focus. An International Journal of Biological and Physical Sciences. Faculty of Pure and Applied Sciences, LAUTECH, Ogbomoso 2018, Vol. 23 (2), 1pp 40155

[26] A. Yekinni, T. Rabiu, I. Adigun, D. Sogunro, R. Saheed and O. Ademolu. "Recycled Aluminium Cans/Rice Husk Ash: Evaluation of Physico-Mechanical Properties". World Journal of Engineering Research and Technology. 2019, Volume 5, Issue 1, pp 18-32

[27] B. Subramaniam, B. Natarajan, B. Kaliyaperumal, and S.J.S Chelladura. "Investigation on mechanical properties of aluminium 7075 - boron carbide - coconut shell fly ash reinforced hybrid metal matrix composites", China Foundry, 2018, Vol 15, No 6, 449-456.

[28] P.V. Rajesh, M.S Prasanth, V.S Daniel and C.M Saravanan. Evaluation of Mechanical Properties and Machinability Analysis of Al 6061 Hybrid Composite. International Journal of Multidisciplinary and Current Research, 2018, Vol 6, $250-255$.

[29] T. Nithyanandhan, K. Rohith, C.G. Sidharath, C. Sachin and S. Jagadesh. "Investigation of Mechanical Properties on Aluminium Based Hybrid Composites". International Journal of Innovative Research in Science, Engineering and Technology. Volume 6, Special Issue 7, April $20175^{\text {th }}$ National Conference on Trends in Automotive Parts Systems and Applications pp 118-126. 
[30] P.L. Rajan, S.U.M Said and T.M. Amruth. "Design and Analysis of Composite of Aluminium, Coconut Shell Ash and SiC Based Clutch Plate Facing”. International Journal of Science, Engineering and Management (IJSEM), 2019, Vol 4, Issue 6, pp 19-26.

[31] M. Poornesh., X.S Johnson, S. Jevy, Singh and G.M.P, Gaurav. "Effect of Coconut Shell Ash and SiC Particles on Mechanical Properties of Aluminium Based Composites". American Journal of Materials Science 2017, 7(4): pp 112-115 DOI: $10.5923 /$ j.materials.20170704.09

[32] L. Arulmani and S.S Kumar. "Experimental Investigation of Aluminium 7075Bagasse Ash-Graphite Composites" International Journal of Materials Science, 2016, ISSN 0973-4589 Volume 11, Number 1, pp 27-31.

[33] S.A. Bello, J.O. Agunsoye, J.A Adebisi, F.O Kolawole and S.B Hassan. "Physical Properties of Coconut Shell Nanoparticles".. Kathmanda University of Science, Engineering and Technology, 2016, Vol 12, No 1, pp 63-79.

[34] M. Kenny and T. Oates. Lime and Limestone', in Ullmann's Encyclopedia of Industrial Chemistry, Weinheim, Germany: Wiley-VCH Verlag GmbH \& Co. KGaA, 2007.

[35] M.A Baghchesara, H. Abdizadeh, and H.R Baharvandi. "'Effects of MgO Nano Particles on Microstructural and Mechanical Properties of Aluminum Matrix Composite Prepared via Powder Metallurgy Route", International Journal of Modern Physics: Conference Series, 2012,.5, pp 607-614. 